\title{
Tumour necrosis factor in the bronchoalveolar secretions of infants with the respiratory distress syndrome and the effect of dexamethasone
} treatment

\author{
S H Murch, T T MacDonald, C B S Wood, K L Costeloe
}

\begin{abstract}
Background Tumour necrosis factor $\alpha$ may contribute to the lung damage that occurs in the adult respiratory distress syndrome. Whether it occurs in the lungs of preterm infants with respiratory distress syndrome is unknown.

Methods Tumour necrosis factor $\alpha$ concentrations in the bronchopulmonary secretions of 28 ventilated preterm infants were determined by the enzyme linked immunosorbent assay.

Results Concentrations were low in the first three days of life, being undetectable in nine of the 20 infants whose bronchopulmonary secretions were sampled. From day 4 concentrations were increased and detectable in all but two of 14 infants. Similar concentrations were found in samples taken on days 8-20and 21-40. Greater mean concentrations occurred in those infants requiring oxygen for a long time. In six infants who received dexamethasone treatment for prolonged ventilator dependency treatment was associated with a reduction in tumour necrosis factor $\alpha$ concentrations. Conclusions Tumour necrosis factor may contribute to the neonatal respiratory distress syndrome, as suggested for the adult respiratory distress syndrome. The therapeutic effects of dexamethasone treatment in neonatal respiratory distress syndrome may be mediated, at least in part, by reduced production of pulmonary tumour necrosis factor.
\end{abstract}

Academic Department of Child Health $S$ H Murch C B S Wood K L Costeloe Academic Department of Paediatric Gastroenterology T T MacDonald Medical College of St Bartholomew's Hospital, London ECIA 7BE

Homerton Hospital, London E9 6SR

Reprint requests to: Dr Murch

Accepted 9 October 1991

Among the preterm infants who develop neonatal respiratory distress syndrome some require prolonged ventilatory support for the chronic lung disease of prematurity or bronchopulmonary dysplasia. ${ }^{12}$ This is an increasingly common cause of chronic lung disease in infants, affecting about $20 \%$ of preterm survivors, with up to 7000 new cases a year in the United States. ${ }^{2}$

After the initial phase of damage due to surfactant deficiency, barotrauma, and oxygen toxicity, local inflammation is important in the progression to chronic lung disease. ${ }^{3}$ Corticosteroids have been used to limit inflammatory damage and are usually given after two to four weeks. ${ }^{12}$
The cytokine tumour necrosis factor $\alpha$ is a potent mediator of pulmonary inflammation, in addition to its better known systemic effects. ${ }^{45}$ It has been postulated that local pulmonary production by alveolar macrophages contributes to the adult respiratory distress syndrome, ${ }^{6-9}$ but its production in the respiratory distress syndrome of infancy has not been documented. We determined tumour necrosis factor $\alpha$ concentrations in pulmonary secretions in infants with the respiratory distress syndrome and the effect of treatment with dexamethasone on the concentrations of tumour necrosis factor $\alpha$ in airways secretions.

\section{Methods}

PATIENTS STUDIED

Twenty eight preterm infants (24-31 weeks' gestation, birth weight $570-2200 \mathrm{~g})$ were studied. All required assisted ventilation for the respiratory distress syndrome (for 4-73 days). Two infants died during the study, one from early progressive lung damage and the other after intraventricular haemorrhage. Eleven of the infants had an uncomplicated course, being weaned from the ventilator and on to room air within 28 days. Six developed mild chronic lung disease, requiring supplemental oxygen for up to 60 days, and a further nine developed more severe bronchopulmonary dysplasia, requiring oxygen for 70-160 days.

Six infants were treated with dexamethasone, five at the age of 28 days because they needed prolonged ventilation. All five improved and four were extubated within five days. The sixth was treated at 14 days for severe lung disease of early onset and did not improve.

\section{EXCLUSIONS}

Samples from infants with known septicaemia or with a clinical or radiological diagnosis of pneumonia were excluded. All ventilated infants had tracheal aspirates sent for microbiological assessment twice weekly. Specimens from any infant known to have secretions colonised with bacteria were also excluded.

COLLECTION OF SAMPLES

Collection of the samples of bronchopulmonary secretions was almost identical to the routine protocol for care of endotracheal tubes, which is performed four hourly in our unit; the methods of collection and analysis were based 


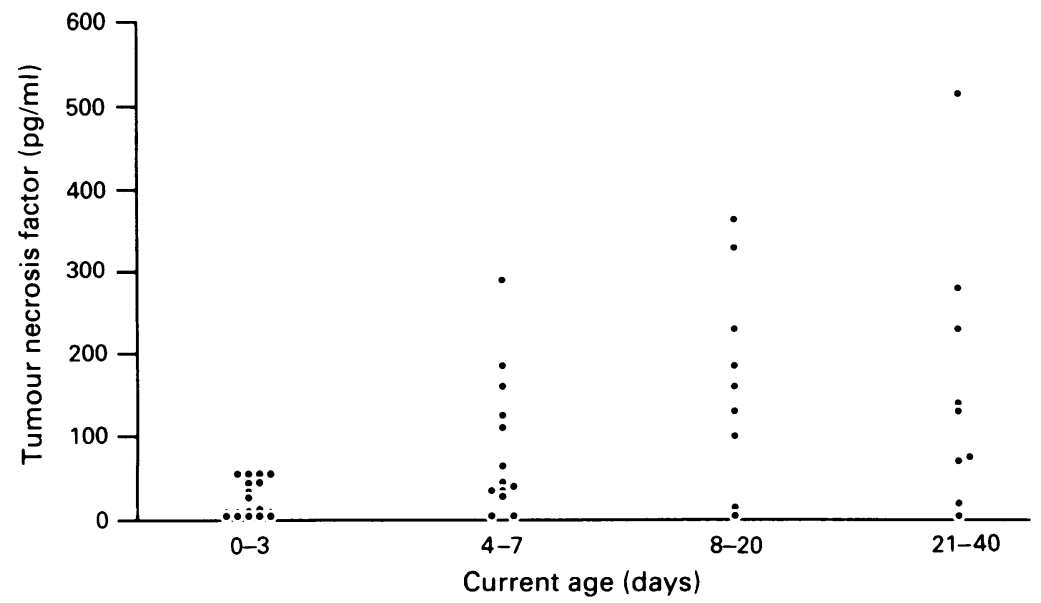

Figure 1 Concentration of tumour necrosis factor $\alpha$ (TNF) in bronchopulmonary lavage fluid, obtained from 28 preterm ventilated infants, shown against age in days at time of sampling. Each point represents the mean concentration of tumour necrosis factor $\alpha$ for one infant in that particular age range.

on those of Millar et al. ${ }^{6}$ Sterile $0.9 \%$ saline $(0.5 \mathrm{ml} \mathrm{kg}$ body weight) was instilled into the endotracheal tube and the ventilator reconnected. After 5-10 breaths a soft 6-8 FG catheter was inserted to just beyond the tip of the endotracheal tube and suction applied. The suction catheter was lavaged with a further $0.25 \mathrm{ml}$ saline $/ \mathrm{kg}$ and all the lavage fluid was frozen immediately for later analysis. Lavages were performed about once every two days during the first week of life, once every two to four days during the succeeding two weeks, and less frequently thereafter.

MEASUREMENT OF TUMOUR NECROSIS FACTOR $\alpha$ The concentration of tumour necrosis factor $\alpha$ in lavage fluid and serum was determined with a commercially available assay (Biokine tm, T Cell Sciences, Cambridge, Massachusetts) with a lower limit of sensitivity of $10 \mathrm{pg} / \mathrm{ml}$.

\section{STATISTICAL ANALYSIS}

Individual concentrations of tumour necrosis

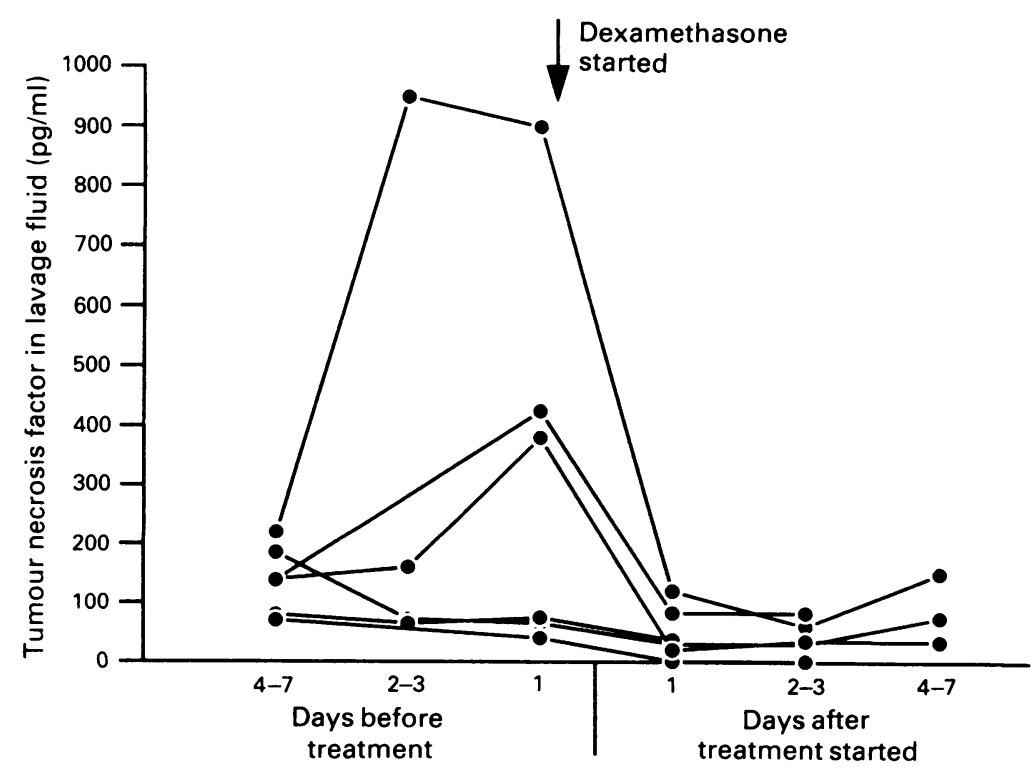

Figure 2 Effect of dexamethasone on bronchopulmonary tumour necrosis factor $\alpha$ (TNF) concentrations in endotracheal tube lavage fluid in six treated infants, showing the concentrations of each infant in the week before and after the start of treatment. factor $\alpha$ in lavage fluid for each infant in a given age range (from 1 to 3 results) were averaged (figure 1). Comparison between these groups at different ages was made with the KolmogorovSmirnov two group test, as were any additional comparisons using these groups. The MannWhitney $U$ test was used for comparison between the groups with the uncomplicated respiratory distress syndrome and those needing prolonged oxygen treatment, a mean tumour necrosis factor concentration for all measurements after day 3 having been derived for each infant. The Mann-Whitney $U$ test was also used to compare tumour necrosis factor concentrations before and after treatment in the infants given dexamethasone (fig 2), and concentrations in infants with and without infection or colonisation of secretions.

\section{Results}

TUMOUR NECROSIS FACTOR $\alpha$ AND AGE

Tumour necrosis factor $\alpha$ was detectable in airways secretions during the first 3 days of life in 11 of 20 infants, but levels were generally low, on average $<55 \mathrm{pg} / \mathrm{ml}$ (fig 1). The levels were significantly higher in the secretions sampled on days 4-7 $(p<0.05)$, days $8-20$ $(\mathrm{p}<0.001)$ and days 21-40 $(\mathrm{p}<0.001)$. There was no progressive increase, and it was not possible to differentiate between the groups after day 4. All serially sampled infants demonstrated an increase in tumour necrosis factoralpha concentration with time; of fourteen infants sampled beyond day 8 , three reached maximal levels between days 4 and 7 , eight did so between days 8 and 20 and a further three did not reach maximal levels until after day 21 .

TUMOUR NECROSIS FACTOR $\alpha$ IN SERUM AND AIRWAYS SECRETIONS

There was no relation between tumour necrosis factor $\alpha$ in lavage fluid and serum samples taken within two hours of lavage; serum concentrations were all below $40 \mathrm{pg} / \mathrm{ml}$. Serum concentrations in the ventilated preterm infants did not differ significantly from those in 30 well preterm or 14 term infants (data not shown).

TUMOUR NECROSIS FACTOR $\alpha$ AND OUTCOME Only three of 11 infants weaned from the ventilator and on to room air within 28 days had a mean tumour necrosis factor $\alpha$ level above 100 $\mathrm{pg} / \mathrm{ml}$ after day 3 and none had a concentration above $250 \mathrm{pg} / \mathrm{ml}$ in lavage fluid. Post day 3 levels were greater in the group needing prolonged oxygen treatment beyond 28 days (11 of 15 with a mean above $100 \mathrm{pg} / \mathrm{ml}$, three above $250 \mathrm{pg} / \mathrm{ml} ; \mathrm{p}<0.02$ ).

\section{EFFECTS OF BACTERIAL COLONISATION}

The airway secretions of four infants became colonised with coagulase negative staphylococci, with no clinical evidence of infection. Their secretions showed no higher peak tumour necrosis factor $\alpha$ concentrations (median 60 range $28-170 \mathrm{pg} / \mathrm{ml}$ ) than did the non-colonised infants (fig 1). Three infants suffered four episodes of proved bacterial pneumonia (one case each of group B streptococci and Klebsiella sp and two of coliforms). 
The concentration of tumour necrosis factor $\alpha$ in lavage fluid was substantially higher in each episode and in the group than in either the uncolonised infants or those colonised with coagulase negative staphylococci (median 658, range $355-1540 \mathrm{pg} / \mathrm{ml} ; \mathrm{p}<0.01$ ).

\section{EFFECTS OF DEXAMETHASONE}

Each of the six infants given dexamethasone had a lower lavage tumour necrosis factor $\alpha$ concentration on the day after treatment than on the day before treatment (fig 2), with a reduction of the group median concentration ( $p<0.03)$. The overall post-treatment tumour necrosis factor $\alpha$ concentration (calculated by using the median post-treatment concentration for each infant to derive a group median) was also lower than the pretreatment concentrations (again based on individual pretreatment medians (36, range $5-120 \mathrm{pg} / \mathrm{ml} v 115$, range $55-900 \mathrm{pg} / \mathrm{ml} ; \mathrm{p}<0.05))$. The three infants with the greatest fall with treatment showed rapid clinical improvement and were extubated within five days.

\section{Discussion}

Tumour necrosis factor $\alpha$ was present in the bronchopulmonary secretions of ventilated preterm infants with the respiratory distress syndrome, higher after 4 days of age than earlier. Greater concentrations occurred in infants needing prolonged oxygen treatment, and tumour necrosis factor $\alpha$ concentrations were reduced in six infants by dexamethasone treatment. A formal bronchoalveolar lavage technique was not used as we were concerned in this pilot study not to deviate from the routine lavage these unwell preterm infants receive. Having found high concentrations of tumour necrosis factor $\alpha$ in bronchopulmonary secretions, we think it now justified to subject preterm infants to more formal lavage techniques in subsequent studies of cytokine production in the lungs.

Although our sampling technique did not allow precise quantification of bronchoalveolar concentrations or localisation of tumour necrosis factor $\alpha$ production, we consider that tumour necrosis factor $\alpha$ at moderate to high concentration may have a role in the inflammatory processes that predispose to neonatal chronic lung disease (serum levels above 100 $\mathrm{pg} / \mathrm{ml}$ have adverse prognostic significance in septicaemia ${ }^{4}$ ).

The time course of tumour necrosis factor $\alpha$ production in our study appears to correlate with known patterns of alveolar macrophage influx in the respiratory distress syndrome. ${ }^{1011}$ Epithelial fragments predominate for the first two to three days, but by day three or four there is a rapid increase in polymorphonuclear neutrophils and activated alveolar macrophages. By day 8 the alveolar macrophage is the predominant cell. ${ }^{10}$ Infants who progress to chronic lung disease show persistently increased numbers of neutrophils in lavage fluid. ${ }^{11}$

After the primary insult in the first days of life there is an inflammatory response, ${ }^{3}$ more pronounced in those who develop bronchopul- monary dysplasia, which is associated with an increased ratio of proteases to protease inhibitors. ${ }^{11}{ }^{12}$ High concentrations of fibronec$\operatorname{tin}^{13}$ may contribute to monocyte chemotaxis ${ }^{14}$ and possibly also to fibrosis. ${ }^{13}$ Alveolar macrophages from preterm infants produce free radicals, the concentrations of which are increased in infants with bronchopulmonary dysplasia and decreased in those receiving glucocorticoid treatment. ${ }^{15}$ Alveolar macrophages in vitro produce large amounts of tumour necrosis factor $\alpha$ on being stimulated ${ }^{16}$ and in animals and man pharmacological doses can directly cause lung damage. ${ }^{917} 18$ High concentrations of tumour necrosis factor $\alpha$ occur in bronchoalveolar secretions of adults with the adult respiratory distress syndrome ${ }^{67}$ and may be a mediator of injury in this condition, ${ }^{89}$ which has many similarities to the neonatal respiratory distress syndrome.

Tumour necrosis factor $\alpha$ may potentially induce lung damage by polymorph chemotaxis, endothelial localisation, and stimulation of the respiratory burst, ${ }^{41920}$ and neutropenia has been shown to protect animals against pulmonary damage induced by tumour necrosis factor $\alpha{ }^{21}$ It may also stimulate production of other mediators and contribute to pulmonary fibrosis. ${ }^{42324}$ Of potential relevance in the neonatal respiratory distress syndrome is the finding, in vitro, that tumour necrosis factor $\alpha$ inhibits expression of pulmonary surfactant proteins SP-A and SP-B, ${ }^{25}$ which appear necessary for normal surfactant function. ${ }^{26}$

The finding of local production of tumour necrosis factor $\alpha$ by the age of 4 days in the neonatal respiratory distress syndrome suggests several therapeutic possibilities. Corticosteroids, which decrease both synthesis and release of tumour necrosis factor $\alpha,{ }^{45}$ are widely used in infants with chronic lung disease and may improve pulmonary compliance, ${ }^{27}$ reduce alveolar proteinase activity, ${ }^{28}$ and, frequently, decrease the duration of ventilation and improve outcome. ${ }^{129}$ They are normally given at 2-4 weeks of age, when it is already clear that the infant has sustained chronic damage. If inflammatory mediators, such as tumour necrosis factor $\alpha$, are produced within the first week, possibly earlier corticosteroid treatment would benefit the at risk infant-perhaps with nebulised rather than systemic drugs to avoid the risks of systemic treatment at this age. Cyclooxygenase inhibitors also attenuate the systemic effects of tumour necrosis factor $\alpha$ though without altering its production ${ }^{5}$; perhaps therefore non-steroidal anti-inflammatory drugs such as indomethacin may influence lung injury. Finally, there may eventually be a role for monoclonal antibodies to tumour necrosis factor $\alpha$, which have been given with apparent benefit to adults with severe septic shock. ${ }^{30}$

This work was supported by the Aylwen Bursary of the Medical College of St Bartholomew's Hospital and by the Welloome Trust. Further studies are being supported by Action Research.

1 Greenough A. Bronchopulmonary dysplasia: early diagnosis, prophylaxis and treatment. Arch Dis Child 1990, 65:1082-8. 
2 Northway WH. Bronchopulmonary dysplasia: then and now. Arch Dis Child 1990;65:1076-81.

3 Robertson B. The evolution of neonatal respiratory distress syndrome into chronic lung disease. Eur Respir J 1989; 2(suppl 3):33-7S

4 Tracey KJ, Vlassara H, Cerami A. Cachectin/tumour necrosis factor. Lancet 1989;i:1122-6.

5 Sherry B, Cerami A. Cachectin/tumour necrosis factor exerts endocrine, paracrine and autocrine control of inflammatory responses. $J$ Cell Biol 1988;107:1269-77.

6 Millar AB, Foley NM, Johnson N McI, Meager A, Rook GAW. Tumour necrosis factor in bronchopulmonary secretions of patients with adult respiratory distress syndrome. Lancet 1989;ii:712-4.

7 Roberts DJ, Davies JM, Evans CC, Bell M, Mostafa SM, Lamche $H$. Tumour necrosis factor and adult respiratory distress syndrome. Lancet 1989;ii:1043-4.

8 Tracey KJ, Lowry SF, Cerami A. Cachectin/TNF $\alpha$ in septic shock and adult respiratory distress syndrome. Am Rev Respir Dis 1988;138:1377-9.

9 Ferrari-Baliviera E, Mealy K, Smith RJ, Wilmore DW. Tumor necrosis factor induces adult respiratory distress syndrome in rats. Arch Surg 1989;124:1400-5.

10 Merritt TA, Puccia J, Edwards DK, Shapiro DL. Newborn tracheal aspirate cytology: classification during respiratory distress syndrome and bronchopulmonary dysplasia. J Pediatr 1981;98:949-56.

11 Ogden BE, Murphy SA, Saunders GC, Pathak D, Johnson JD. Neonatal lung neutrophils and elastase/proteinase inhibitor imbalance. Am Rev Respir Dis 1984;130:817-21.

12 Merritt TA, Cochrane CG, Holcomb K, Bohl B, Hallman $\mathrm{M}$, Strayer $\mathrm{P}$, et al. Elastase and $\alpha 1$-proteinase inhibitor activity in tracheal aspirates during respiratory distress syndrome. J Clin Invest 1983;72:656-66.

13 Gerdes JS, Yoder MC, Douglas SD, Paul M, Harris MC, Polin RA. Tracheal lavage and plasma fibronectin: relationship to respiratory distress syndrome and development of bronchopulmonary dysplasia. J Pediatr 1986; 108:601-6.

14 Doherty DE, Henson PM, Clark RAF. Fibronectin fragments containing the RGDS cell-binding domain mediate monocyte migration into the rabbit lung. J Clin Invest 1990;86:1065-75.

15 Clement A, Chadelat K, Sardet A, Grimfeld A, Tournier G. Alveolar macrophage status in bronchopulmonary dysplasia. Pediatr Res 1988;23:470-3.

16 Martinet Y, Yamauchi K, Crystal R. Differential expression of the tumor necrosis factor/cachectin gene by blood and lung mononuclear phagocytes. Am Rev Respir Dis 1988; 138:659-65.
17 Kuei JH, Tashkin DP, Figlin RA. Pulmonary toxicity of recombinant tumor necrosis factor. Chest 1989;96:334-8.

18 Warren JS, Yabroff KR, Remick DG, Kunkel SL, Chensue $\mathrm{SW}$, Kunkel RG, et al. Tumor necrosis factor participates in the pathogenesis of immune complex alveolitis in the rat. J Clin Invest 1989;84:1873-82.

19 Gamble JR, Harlan JM, Klebanoff SJ, Vadas MA. Stimulation of the adherence of neutrophils to umbilical vein endothelium by human recombinant tumor necrosis factor. Proc Natl Acad Sci USA 1985;82:8667-71.

20 Nathan CF. Neutrophil activation on biological surfaces: massive release of hydrogen peroxide in response to products of macrophages and lymphocytes. $J$ Clin Invest 1987;80:1550-60.

21 Stephens KE, Ishizaka A, Wu Z, Larrick JW, Raffin TA. Granulocyte depletion prevents tumor necrosis factorinduced lung injury in guinea-pigs. Am Rev Respir Dis 1988;138:1300-7.

22 Standiford TJ, Kunkel SL, Basha MA, Chensue SW, Lynch JP, Toews GB, et al. Interleukin-8 gene expression by a pulmonary epithelial cell line: a model for cytokine pulmonary epithelial cell line: a model for cyto

23 Postlethwaite AE, Seyer JM. Stimulation of fibroblast chemotaxis by human recombinant tumor necrosis factor $\alpha($ TNF- $\alpha)$ and a synthetic TNF- $\alpha 31-68$ peptide. $J$ Exp Med 1990;172:1749-56.

24 Antoniades HN, Bravo MA, Avila RE, Galanopoulos T, Neville-Golden J, Maxwell M, et al. Platelet-derived growth factor in idiopathic pulmonary fibrosis. $J$ Clin Invest 1990;86:1055-64.

25 Wispé JR, Clark JC, Warner BB, Fajardo D, Hull WE, Holtzman RB, et al. Tumor necrosis factor-alpha inhibits expression of pulmonary surfactant protein. J Clin Invest 1990;86:1954-60.

26 Weaver TE. Pulmonary surfactant-associated proteins. Gen Pharmacol 1988;19:361-8.

27 Gladstone IM, Ehrenkranz RA, Jacobs HC. Pulmonary function tests and fluid balance in neonates with chronic function tests and fluid balance in neonates with chronic 1989;84:1072-6.

28 Gerdes JS, Harris MC, Polin MD. Effects of dexamethasone and indomethacin on elastase, $\alpha 1$-proteinase inhibitor and fibronectin in bronchoalveolar lavage fluid in neonates. $J$ Pediatr 1988;113:727-31.

29 Cummings JJ, D'Eugenio DB, Gross SJ. A controlled trial of dexamethasone in infants at high risk for bronchopulmonary dysplasia. N Engl J Med 1989;320:1505-10.

30 Exley AR, Cohen J, Burman W, Owen R, Hanson G, Lumley $\mathrm{J}$, et al. Monoclonal antibody to TNF in severe septic shock. Lancet 1990;335:1275-7. 